\title{
Impact of Different Grinding Aids on Standard Deviation in X-Ray Fluorescence Analysis of Cement Raw Meal
}

\author{
Andrew Aondoaver Tyopine ${ }^{1}$, Aondo Joseph Wangum ${ }^{2}$, Edwin Ameh Idoko ${ }^{3}$ \\ ${ }^{1}$ Department of Chemistry/Biochemistry/Molecular Biology, Faculty of Science and Technology, Federal \\ University Ndufu Alike, Ikwo, Nigeria \\ ${ }^{2}$ Department of Chemistry, Faculty of Sciences, Benue State University, Makurdi, Nigeria \\ ${ }^{3}$ Department of Chemistry, College of Sciences, Federal University of Agriculture, Makurdi, Nigeria \\ Email: andrewtyopine@gmail.com, wangumaondo@yahoo.com, eddycicero@gmail.com
}

Received 1 March 2015; accepted 22 April 2015; published 27 April 2015

Copyright (C) 2015 by authors and Scientific Research Publishing Inc.

This work is licensed under the Creative Commons Attribution International License (CC BY).

http://creativecommons.org/licenses/by/4.0/

cC) (i) Open Access

\begin{abstract}
X-ray fluorescence (XRF) analysis utilizes particle size which is resulted from milling of a material. The milling ensures uniform and fine grained powder. The finer and more uniform the particle size is, the better the result and easier it is for material quality control. To ensure uniformity in particle size and finer powder, a comparative analysis was conducted with different grinding aids and pressed pellet method was used in obtaining analysis results. Pressed pellets of cement raw meal sample milled with different grinding aids (graphite, aspirin and lithium borate) were subjected to XRF. Graphite produced better particle size uniformity with a corresponding standard deviation that made quality control of raw meal easier and better than aspirin and lithium borate.
\end{abstract}

\section{Keywords}

X-Ray Fluorescence, Pressed Pellets, Standard Deviation, Grinding Aid, Particle Size Uniformity, Comparative Analysis, Cement Raw Meal, Quality Control

\section{Introduction}

X-ray fluorescence (XRF) has wide industrial application. It is applied in the cement industry for quality control of material since accurate and rapid determinations are critical. XRF is known for rapid and accurate analysis. However its problems include absorption, mineralogical variations among samples and particle size effects

"Corresponding author.

How to cite this paper: Tyopine, A.A., Wangum, A.J. and Idoko, E.A. (2015) Impact of Different Grinding Aids on Standard Deviation in X-Ray Fluorescence Analysis of Cement Raw Meal. American Journal of Analytical Chemistry, 6, 492-494. 
which often influence the intensities of analytical lines [1].

$\mathrm{XRF}$ is best applied to materials where the compositional variation is small. This makes quality control of cement easier. Small variations in composition, reproducibility and accuracy of XRF analysis are affected by uniformity of particle size and size of powder grain of samples.

The reproducible and accurate results in XRF analysis require proper sample preparation in order to minimize intensity variations in the particle size distribution. Intensity increases with decrease in particle size [2], because there is more penetration of incident X-ray. To achieve consistency in uniformity of particle size with a view to effective quality control, finer grinding is achieved with grinding aid.

There are studies on particle size effects on XRF where angle of intensity of incident X-rays was shown to be dependent on particle size [3] [4], but this research focuses on studying the effect of particle size on standard deviation from XRF analysis of cement raw meal samples in quality control. Therefore the research aims to: compare particle size distribution when cement raw meal is ground with graphite, lithium borate and aspirin as grinding aids and to establish which grinding aid would produce the least standard deviation suitable for easier and better cement raw meal quality control.

\section{Sample Preparation}

10 g cement raw meal sample was ground with grinding aid for 130 seconds at $1200 \mathrm{rpm}$. The sieve results in Table 1 shows residue by way of sieve analysis using $45 \mu \mathrm{m}$ sieve mesh (BS140-1). A total of nine (9) cement raw meal samples each weighing $10 \mathrm{~g}$ with varying combinations of grinding aid were milled using a Pfaff grinding machine for 130 secs at $1200 \mathrm{rpm}$. The resulting powders were pelletized into circular discs. Each disc pellet was analyzed using XRF analyzer (ARL 9900 oasis) and the standard deviations per grinding aid combination were generated.

The grinding aids were graphite (98\%, purchased from blue sea Nigeria Ltd.), lithium borate (99\%, purchased from FLS Germany) and aspirin was purchased from king size pharmaceuticals Nigeria Ltd.

\section{Results and Discussion}

Table 1 shows the particle distribution by way of sieve residue using $45 \mu \mathrm{m}$ sieve mesh. Cement raw meal ground with aspirin gave least residue followed by graphite and lithium borate having the highest residue. This means there is better particle uniformity and finer powder with aspirin than graphite and lithium borate when used independently or combined.

Tables 2-4 show standard deviation in lime saturation factor (LSF) derived from chemical analysis of cement raw meal ground with various grinding aids.

Table 1. Percentage residue on $45 \mu \mathrm{m}$ sieve mesh.

\begin{tabular}{cccc}
\hline Grinding aid & Initial sample weight & Final residue weight & \% residue \\
\hline Graphite and lithium borate & $10 \mathrm{~g}$ & $1.27 \mathrm{~g}$ & 12.70 \\
Aspirin and lithium borate & $10 \mathrm{~g}$ & $0.94 \mathrm{~g}$ & 9.40 \\
Lithium borate & $10 \mathrm{~g}$ & $2.96 \mathrm{~g}$ & 29.60 \\
\hline
\end{tabular}

Table 2. Standard deviation from XRF analysis of sample ground with graphite and lithium borate.

\begin{tabular}{|c|c|c|c|c|}
\hline & 1 & 2 & 3 & $\mathrm{AV}$ \\
\hline $\mathrm{SiO}_{2}$ & 13.62 & 13.69 & 13.65 & 13.65 \\
\hline $\mathrm{Al}_{2} \mathrm{O}_{3}$ & 4.00 & 4.00 & 3.98 & 3.99 \\
\hline $\mathrm{Fl}_{2} \mathrm{O}_{3}$ & 1.86 & 1.88 & 1.87 & 1.87 \\
\hline $\mathrm{CaO}$ & 41.72 & 41.69 & 41.70 & 41.70 \\
\hline LSF & 94.70 & 94.14 & 94.53 & 94.46 \\
\hline SD & \multicolumn{4}{|c|}{0.27} \\
\hline
\end{tabular}


Table 3. Standard deviation from XRF analysis of sample ground with aspirin and lithium borate.

\begin{tabular}{|c|c|c|c|c|}
\hline & 1 & 2 & 3 & $\mathrm{AV}$ \\
\hline $\mathrm{SiO}_{2}$ & 12.91 & 12.95 & 12.94 & 12.93 \\
\hline $\mathrm{Al}_{2} \mathrm{O}_{3}$ & 4.18 & 4.20 & 4.20 & 4.19 \\
\hline $\mathrm{Fl}_{2} \mathrm{O}_{3}$ & 1.86 & 1.88 & 1.87 & 1.87 \\
\hline $\mathrm{CaO}$ & 40.80 & 40.72 & 40.92 & 40.81 \\
\hline LSF & 96.52 & 95.60 & 96.60 & 96.24 \\
\hline SD & \multicolumn{4}{|c|}{0.57} \\
\hline
\end{tabular}

Table 4. Standard deviation from XRF analysis of sample ground with lithium borate.

\begin{tabular}{|c|c|c|c|c|}
\hline & 1 & 2 & 3 & $\mathrm{AV}$ \\
\hline $\mathrm{SiO}_{2}$ & 14.67 & 14.73 & 14.85 & 14.75 \\
\hline $\mathrm{Al}_{2} \mathrm{O}_{3}$ & 4.26 & 4.28 & 4.25 & 4.26 \\
\hline $\mathrm{Fl}_{2} \mathrm{O}_{3}$ & 1.84 & 1.85 & 1.84 & 1.84 \\
\hline $\mathrm{CaO}$ & 43.13 & 43.14 & 42.94 & 43.07 \\
\hline LSF & 91.18 & 90.87 & 89.36 & 90.47 \\
\hline SD & \multicolumn{4}{|c|}{0.68} \\
\hline
\end{tabular}

Sieve analysis as shown in Table 1 revealed that finer particles could be achieved when aspirin is used with lithium borate. It gave $9.40 \%$ residue on $45 \mu \mathrm{m}$. This is least when compared to graphite with lithium borate and lithium borate alone. The impact of using aspirin with lithium borate translates into a lower standard deviation as shown in Table 3 when compared to that obtained when using only lithium borate as grinding aid revealed in Table 4. However it is not a good choice for industrial quality control of cement raw meal where speed is required. It had rough surface when pressed into a pellet and had high breakage frequency before few could be analyzed. Its rough surface produced higher standard deviation than that of graphite with lithium borate (Table 2). Cement meal pellet produced with graphite and lithium borate produced $12.70 \%$ residue on $45 \mu \mathrm{m}$ which is less than that produced by lithium borate alone (Table 1). Both of them produced smooth surface and robust pellets which supports speed of sample preparation. However graphite with lithium borate yielded least standard deviation (Table 2). This may be attributed to non stickiness of sample particles when ground with graphite-lithium borate grinding aid mixture which minimizes scattering of reflected rays from surface of pellet.

\section{Conclusion}

Graphite with lithium borate gave a consistent lower standard deviation from analysis of a number of samples as compared with lithium borate. The implication is that there was less material adjustment during quality control. Cement control process parameters improved and quality control with the grinding aid mixture produced larger tons of material with consistent composition and consequently better quality.

\section{References}

[1] Bradner, D.W. (1999) Analysis of Limestone and Dolomites by X-Ray Fluorescence. Rigaku Journal, 16, 16-18.

[2] Burnstein, F. (1962) Particle Size and Mineralogical Effects in Mining Applications of X-Ray Analysis. Denver Research Institute, University of Denver, Denver.

[3] Maruyama, Y., Shirai, K., Yamamoto, Y., Okada, T. and Kato, M. (2006) Laboratory Experiments of X-Ray Fluorescence Simulating Lunar and Planetary Rough Surfaces. Kato, M. and Tanaka, S., Eds., Proceedings of the ISAS Lunar and Planetary Symposium, ISAS, Sagamihara, 38.

[4] Maruyama, Y., Ogawa, K., Okada, T. and Kato, M. (2007) Particle Size Effect in X-Ray Fluorescence and Its Implication to Planetary XRF Spectroscopy. Lunar Planet Science, 38, 1186. 